\title{
Immunocytochemical Mapping of an RDL-Like GABA Receptor Subunit and of GABA in Brain Structures Related to Learning and Memory in the Cricket A cheta domesticus
}

Colette Strambi, ${ }_{1,3}^{1,3}$ Myriam Cayre, ${ }^{1,2}$ David B. Sattelle, ${ }^{2}$ Roger Augier, ${ }^{1}$ Pierre Charpin, ${ }^{1}$ and Alain Strambi ${ }^{1}$

${ }^{1}$ Centre National de la Recherche Scientifique (CNRS)

Laboratoire de Neurobiologie

13402 Marseille Cedex 20, France

${ }^{2}$ Laboratory of Molecular Signaling

Department of Zoology

The Babraham Institute

Cambridge CB2 3ES, UK

\section{Abstract}

The distribution of putative RDL-like GABA receptors and of $\gamma$-aminobutyric acid (GABA) in the brain of the adult house cricket Acheta domesticus was studied using specific antisera. Special attention was given to brain structures known to be related to learning and memory. The main immunostaining for the RDL-like GABA receptor was observed in mushroom bodies, in particular the upper part of mushroom body peduncle and the two arms of the posterior calyx. Weaker immunostaining was detected in the distal part of the peduncle and in the $\alpha$ and $\beta$ lobes. The dorso- and ventrolateral protocerebrum neuropils appeared rich in RDL-like GABA receptors. Staining was also detected in the glomeruli of the antennal lobe, as well as in the ellipsoid body of the central complex. Many neurons clustered in groups exhibit GABA-like immunoreactivity. Tracts that were strongly immunostained innervated both the calyces and the lobes of mushroom bodies. The glomeruli of the antennal lobe, the ellipsoid body, as well as neuropils of the dorso- and ventrolateral protocerebrum were also rich in GABA-like immuno-

${ }^{3}$ Corresponding author. reactivity. The data demonstrated a good correlation between the distribution of the GABA-like and of the RDL-like GABA receptor immunoreactivity. The prominent distribution of RDL-like GABA receptor subunits, in particular areas of mushroom bodies and antennal lobes, underlines the importance of inhibitory signals in information processing in these major integrative centers of the insect brain.

\section{Introduction}

In invertebrates as in vertebrates, $\gamma$-aminobutyric acid (GABA) is a major inhibitory neurotransmitter (for reviews, see Sattelle 1990; Sattelle et al. 1991a). Several laboratories have described the distribution of GABA-like immunoreactivity in the central nervous system of insects (for review, see Homberg 1994). Such is the case for Manduca sexta (Hoskins et al. 1986; Homberg et al. 1987; Homberg and Hildebrand 1994), Periplaneta americana (Füller et al. 1989; Bleschmidt et al. 1990), Apis mellifera (Bicker et al. 1985; Schäfer and Bicker 1986), and Schistocerca americana (Leitch and Laurent 1996).

In contrast, relatively few studies have addressed the distribution of insect GABA receptors. In vertebrates, $\mathrm{GABA}_{\mathrm{A}}$ receptors that gate chloride channels have now been identified. They are mem-

LEARN IN G \& MEM ORY 5:78-89 ๑ 1998 by Cold Spring Harbor Laboratory Press ISSN 1072-0502/98 \$5.00

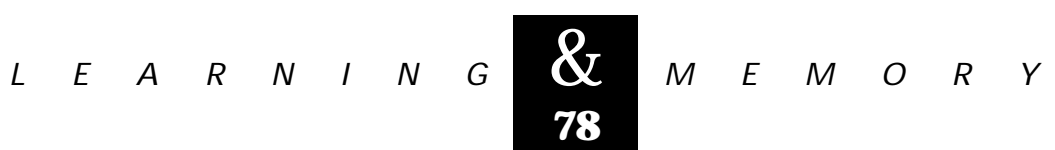


bers of the cys-loop family of ionotropic receptors and are pentameric hetero-oligomers assembled from various combinations of five subunit types $(\alpha$, $\beta, \gamma, \delta, \epsilon)$ that, with the exception of $\delta$ and $\epsilon$, have multiple isoforms (Macdonald and Olsen 1994; Sieghart 1995). Immunoprecipitation studies suggested that most $\mathrm{GABA}_{A}$ receptors are hetero-oligomers of $\alpha, \beta, \gamma$, or $\delta$ subunits, whereas $\mathrm{GABA}_{C}$ receptors, also gating chloride channels, contain $\rho$ subunit isoforms (Sieghart 1995; McKernan and Whiting 1996). In invertebrates, the occurrence of GABA-gated chloride channels (GABARs) is well documented and three putative GABAR subunits, RDL, LCCH3, GRD, have been reported in Drosophila melanogaster (ffrench-Constant et al. 1991; Sattelle et al. 1991b; Henderson et al. 1993; Chen et al. 1994; Harvey et al. 1994).

The RDL subunit of the Drosophila GABA receptor was cloned from an insecticide-resistant mutant named resistance to dieldrin (Rdl) (ffrenchConstant et al. 1991). It allowed the production of polyclonal anti-RDL antibodies, which were used to examine GABA receptor distribution in Drosophila nervous tissue (Aronstein and ffrench-Constant 1995; Harrison et al. 1996) and in Calliphora mushroom bodies (Brotz et al. 1997). Similarly, the distribution of the LCCH3 subunit in Drosophila central nervous system has been described (Aronstein et al. 1996). The antibody generated by Harrison et al. (1996) has also been used to study the localization of putative RDL-like GABA receptor subunits in the cockroach, P. americana (Sattelle et al. 1998).

The most studied integrative pathway involved in insect learning and memory comprises tw o main brain structures: the antennal lobe in deutocerebrum and the mushroom bodies in protocerebrum. The mushroom bodies were found to be the main brain integrative center. Olfactory learning has been particularly well studied in honeybees and Drosophila. Local cooling experiments during bee olfactory conditioning demonstrated the involvement of mushroom bodies in memory formation (Erber et al. 1980). Further studies on the neural netw ork involved in the proboscis extension reflex allowed better analysis of the respective importance of antennal lobe and mushroom bodies in olfactory learning. Thus, mediation of the unconditioned stimulus in associative learning takes place through an octopaminergic neuron that innervates the glomeruli of the antennal lobe, the mushroom body calyx, and the lateral protocerebral neuropil. Another specific neuron, connecting outputs from Kenyon cells and projecting to the lateral protocerebrum was seen to be involved in the conditioned stimulus pathway (Mauelshagen 1993; Hammer and Menzel 1995; Hammer 1997). In Drosophila, deficiency in olfactory learning was observed in mushroom body mutants (Heisenberg et al. 1985). Later on, chemical ablation of mushroom bodies was seen to abolish odor learning (de Belle and Heisenberg 1994). The use of mutants defective in the cyclic AMP (CAMP) system, and presenting altered learning performances allowed to point out the preferential expression in mushroom bodies of the CAMP phosphodiesterase, the adenylate cyclase, and the catalytic subunit of protein kinase $A$, underlining the role of this brain structure in learning and memory (Nighorn et al. 1991; Han et al. 1992; Davis 1993, 1996; Skoulakis et al. 1993). According to recent data, GABA inhibition of the Kenyon cells could play a role on the odorevoked oscillation patterns observed in the mushroom bodies (Laurent and Davidowitz 1994; Laurent et al. 1996; Leitch and Laurent 1996). Morover, experience has been seen to induce structural plasticity in mushroom body neuropils of some adult insects (Technau 1984; Withers et al. 1995; Fahrbach and Robinson 1996). In the adult house cricket, neurogenesis modulated by morphogenetic hormones has been observed in mushroom bodies (Cayre et al. 1994, 1996a, 1997a). A role for this neuronal proliferation is also implied in cricket oviposition, a behavior involving experience and memory (Cayre et al. 1996b, 1997b). Thus, it was of interest to examine the possible presence of receptors for inhibitory signals in brain structures known to be related to learning and memory.

In the present work, we examined the distribution of the RDL-like GABA receptor subunit in the adult nervous system, focusing in particular on antennal lobe and mushroom bodies, and we compared it to the localization of the GABA-like immunoreactivity. We also described the central complex. Although the functional roles of this brain structure are not well understood (for reviews, see Heisenberg 1994; Homberg 1987), it was supposed to play a role in olfactory memory (Heisenberg et al. 1985).

\section{Materials and Methods}

INSECTS

Adult female crickets (Acheta domesticus)

$$
\begin{array}{llllllllllllllll}
L & E & A & R & N & I & N & G & \underset{79}{\mathbf{X}} & M & E & M & O & R & Y
\end{array}
$$


Strambi et al.

were isolated at emergence and reared in standard conditions, at $29^{\circ} \mathrm{C}, 55 \%$ relative humidity, under a 16-hr light/8-hr dark photoperiod. They were fed on rabbit food, wheat germ, and bran; water was continuously available.

\section{IMMUNOCYTOCHEMISTRY}

Immunocytochemical staining was performed on paraffin sections. For studies on RDL-like GABA receptors, the cerebral ganglia were dissected rapidly in saline, then fixed for $12 \mathrm{hr}$ in Bouin solution (one part 35\% formaldehyde, three parts saturated picric acid, plus acetic acid at a final concentration of $5 \%$ ). For GABA-like immunoreactivity, cerebral ganglia were fixed for $2 \mathrm{hr}$ in a solution containing one part $25 \%$ glutaraldehyde and three parts saturated picric acid, acetic acid was added at a final concentration of $1 \%$.

After fixation, the samples were dehydrated through 95\% ethanol (three times for $24 \mathrm{hr}$ ), 1butanol (three times for $24 \mathrm{hr}$ ), and embedded in $56^{\circ} \mathrm{C}$ paraffin. Sections $(6 \mu \mathrm{m})$ were cut and processed for immunocytochemistry. We used polyclonal antibodies raised in rabbits (Harrison et al. 1996). Guided by recent findings (Tu and Hagedorn 1992; Ziegler et al. 1995), the avidin-biotin process was avoided and immunoreactivity was revealed indirectly with a secondary antibody labeled with peroxidase (BioRad).

The rehydrated sections were maintained at $4^{\circ} \mathrm{C}$ and treated for $1 \mathrm{hr}$ in a $5 \%$ goat normal serum prepared in $0.1 \mathrm{~m}$ phosphate buffer $(\mathrm{pH} \mathrm{7.2)}$ containing $150 \mathrm{~mm} \mathrm{NaCl}$ (PBS). They were incubated overnight in the primary antibody at a dilution of $1: 200$ in PBS for the GABA receptor antibody and 1:5000 in PBS for the GABA antibody (Sigma). Sections were rinsed $(4 \times 15 \mathrm{~min})$ in PBS containing $500 \mathrm{~mm} \mathrm{NaCl}$, then incubated for $4 \mathrm{hr}$ in the secondary antibody (goat anti-rabbit peroxidase labeled; BioRad) that was diluted in PBS 1:3000. The sections w ere then washed $(4 \times 15 \mathrm{~min})$ in PBS and treated with 3, 3'-diaminobenzidine (DAB; Sigma), according to the process of Witten and Truman (1991). Subsequently, sections were dehydrated, cleared in toluene, mounted in DePeX, and finally photographed with an Axiophot (Zeiss).

\section{Results}

\section{CONTROL EXPERIMENTS}

Sections treated with $D A B$ alone produced no staining in the cricket brain, indicating that endogenous peroxidase was entirely eliminated during fixation and paraffin embedding. Similarly, omission of the primary antibody, or use of the preimmune serum resulted in no labeling (data not shown). The specificity of the anti-RDL antibody has been established elsewhere, by abolition of staining in experiments where the antibody was absorbed with the antibody-raising peptide (Harrison et al. 1996).

\section{DISTRIBUTION OF RDL-LIKE GABA RECEPTORS}

In the cricket A. domesticus, using the RDL carboxy-terminal polyclonal antibody, immunoreactivity was detected in many neuropil regions of the brain. The most intensely labeled structures were the mushroom bodies, especially the upper part of the peduncles. Staining of the different regions was examined in detail, and the main results are summarized in Figure 1.

PROTOCEREBRUM

\section{Mushroom Bodies}

As in most pterygote insects, the Kenyon cells, intrinsic interneurons of the mushroom bodies, appear as numerous small cells densely packed in a cup-like structure, the calyx; they send axons to a peduncle that divides into a medial $(\beta)$ lobe and an ascending $(\alpha)$ lobe. In A. domesticus, as in other Orthoptera (Schürmann 1970, 1972, 1973, 1974, 1987; Weiss 1981), the single calyx comprises an internal anterior calyx partially surrounded by a posterior calyx that expands two arms flanking the top of the peduncle.

Immunoreactive granules can be observed at the periphery of some perikarya of Kenyon cells. In the neuropil of anterior and posterior calyces, a network of poorly labeled fibers can be observed. An intense anti-RDL-like immunoreactivity appeared in the upper part of the peduncle at its entrance into the calyces (Figs. 2, A and B, and $3 A$ ). The two arms of the posterior calyx were intensely labeled (Figs. 2, A and B, and $3 A$ ), as were the large and distinct fiber fascicles that exit from the center of the peduncle and invade the calyx neuropils (Figs. 2, A and B, and $3 A$ ). In sagittal sections, labeling was reduced in the distal part of the peduncle (Fig. 2B). The median unstained core channel of the peduncle (Figs. 2, B and C, and 3, E and F) corresponds to loosely arranged fibers surrounded by concentric, densely packed immuno-

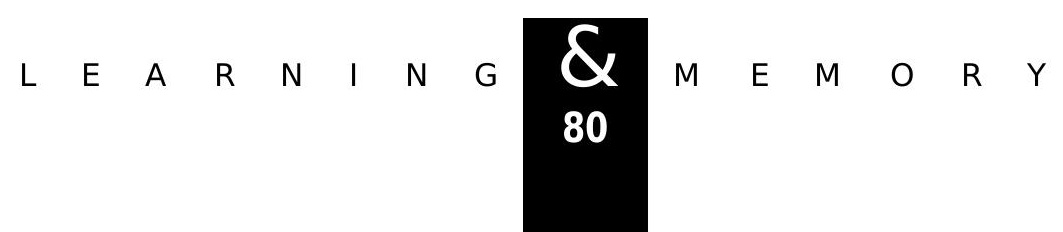




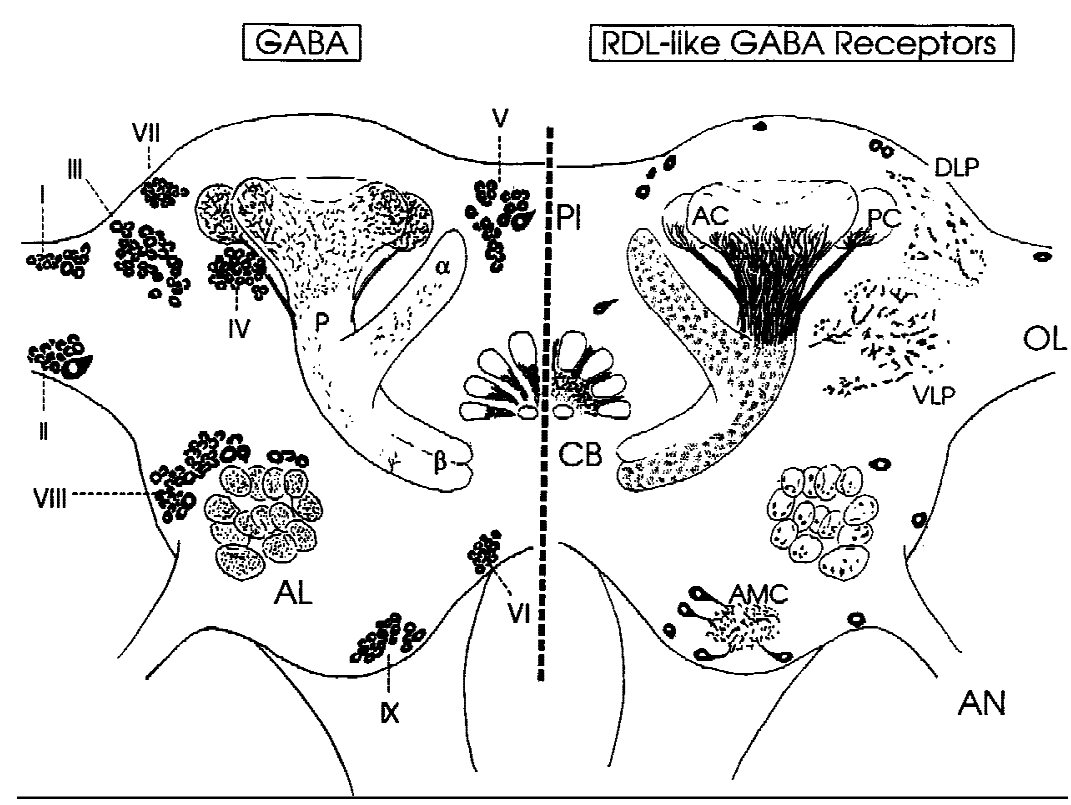

Figure 1: Diagram summarizing, in frontal view, the distribution of RDL-like GABA receptors (right) and of the GABAlike immunoreactivity (left). Except for the mushroom bodies, immunoreactivity in the neuropils has been omitted for clarity. Nine groups (I-X) of GABAergic neurons were indicated as well as neurons immunoreactive to the RDL-GABA receptor subunit antiserum. (AC) Anterior calyx of mushroom body; (PC) posterior calyx of mushroom body; $(P)$ peduncle of mushroom body; $(\alpha) \alpha$ lobe of mushroom body; $(\beta) \beta$ lobe of mushroom body; $(A L)$ antennal lobe; $(C B)$ central body; (OL) optic lobe; (PI) pars intercerebralis; (AN) antennal nerve; (AMC) antennal motor center; (DLP) dorsolateral protocerebrum; (VLP) ventrolateral protocerebrum.

reactive processes. Two strongly stained fiber tracts were found to surround the peduncle (Figs. $2 \mathrm{C}$ and $3 \mathrm{E}$ ) but were indistinguishable in its distal third (Fig. 2B,E). Labeling was also detected in the $\alpha$ and $\beta$ lobes. The loose core structure observed in the peduncle can be followed in the $\alpha$ lobe that contains numerous immunoreactive processes concentrically organized throughout its entire length (Fig. 2G). Several compartments can be distinguished in the $\beta$ lobes that present differences in their immunostaining. On frontal sections (Fig. $2 \mathrm{G}, \mathrm{H})$, strongly labeled fibers can be observed oriented along the main axis and at the margins of the ventral part of the lobe. The dorsal part of the lobe did not reveal any immunoreactivity (Fig. 2G,H). Fiber fascicles having a regular arrangement and a dense immunostaining are projecting betw een the $\alpha$ and $\beta$ lobes (Fig. 4H).

\section{Central Complex}

No label was detected in the protocerebral bridge (Fig. $2 \mathrm{C}$ ) and in the noduli. The neuropils of the central complex, which consist of the protocerebral bridge, the fan-shaped body, the ellipsoid body and the noduli, exhibited different levels of immunoreactivity. The fibers forming the posterior chiasma described by Williams (1975) are immunoreactive. They divide the poorly labeled fanshaped body into eight sections, crossing again at the entrance of the ellipsoid body that appeared moderately stained (Fig. 2D,F). Immunoreactive fi- bers were observed in the isthmus beneath the ellipsoid body (Fig. 2D).

\section{Other Neuropils and Tracts}

The dorsolateral and ventrolateral protocerebrum also contained numerous immunoreactive processes. Some were nerve fiber profiles; however, most corresponded to glial cells whose cell bodies and thin branches showed intense staining (Fig. 3C). Glial cells from other neuropils were unlabeled.

\section{DEUTOCEREBRUM}

The two main structures of the deutocerebrum - the antennal motor center and the antennal lobe-exhibited immunoreactivity. In the antennal motor center, located posteroventrally to the antennal lobe, profiles of numerous immunoreactive processes were observed (Fig. 3G). From four intensely labeled perikarya, situated at the internal and ventral border of this neuropil, axons passed to the antennal motor center. In the glomeruli of the antennal lobe, immunoreactivity was observed as a network of fibers corresponding to synaptic contacts between sensory afferents and local interneurons or relay neurons (Fig. 3H). In frontal sections, four large immunoreactive somata also appeared, three at the internal and one at the external margin of deutocerebrum (see Fig. 1). 


\section{Strambi et al.}

Figure 2: $\mathrm{RDL}$-like GABA receptors in the cricket protocerebrum. $(A)$ Frontal section through the calyces of mushroom bodies. The central part of the anterior calyces (AC) is strongly labeled as well as the two arms of the posterior calyces (arrowheads). (B) Sagittal section through the mushroom body. An intense immunoreactivity is present at the entrance of the peduncle into the anterior calyx (AC), as well as in the arm (arrow) of the posterior calyx (PC). N ote that the strong peripheral labeling observed in the peduncle $(P)$ disappears in the distal portion of this region of the mushroom body. (C) Frontal section through the proximal part of the peduncle $(P)$. Two concentric rings that are strongly immunoreactive surround the peduncle. No label is detected in the protocerebral bridge (PB). Two immunoreactive neurons are visible at the margin of the pars intercerebralis (PI). (D) Frontal section showing the central body. Immunoreactive profiles are present in the isthmus tract (IT) and in the nerve bundles passing to the ellipsoid body (EB). Some labeled processes appear in the subcentral body commissure (SCBCO). (E) Frontal section posterior to $C$. Immunoreactivity is less intense at the periphery of the posterior peduncle $(P)$ (compare with Fig. $3 \mathrm{C})$. The noduli $(\mathrm{N})$ of the central complex, visible under the fan-shaped body (FSB) lack immunoreactivity. (F) Frontal section posterior to $D$. Immunoreactive processes appear between the columns of the fan-shaped body (FSB). The ellipsoid body (EB), and the isthmus tract (IT) are labeled. $(G, H)$ Frontal section of the $\alpha$ and $\beta$ lobes of mushroom body. N ote the heterogeneous distribution of immunoreactivity in the lobes. In the $\alpha$ lobe, the unstained core channel is surrounded by immunoreactive processes parallel to its main axis. Strongly labeled fibers are present at the margins of the ventral part of the $\beta$ lobe. The dorsal part of the $\beta$ lobe is free of any labeling (arrowheads). Immunoreactive processes are present in the median bundle (arrow). Densely immunostained fiber fascicles $(H)$ are projecting between the two lobes of mushroom bodies. $(A-H)$ Bars, $50 \mu \mathrm{m}$.

\section{DEVELOPMENTAL ASPECTS}

For most of this study we examined RDL-like GABA receptors in 5-day-old females. However, some experiments were performed on newly emerged adult animals. In these crickets, only some immunoreactive processes were observed in the dorso- and ventrolateral protocerebrum. The calyces of mushroom bodies and the upper part of the peduncle were not labeled (Fig. 3D,F). Interestingly, these newly emerged adults showed intense staining in the tracheas (Fig. 3D), located at the inner face of the tracheal cells, where a dense immunoreactive deposit was observed (Fig. 3B). This tracheal immunoreactivity rapidly disappeared in the first $24 \mathrm{hr}$ of imaginal life. Only $24 \mathrm{hr}$ after emergence were the RDL-like GABA receptors clearly detected in the various neuropils.

\section{DISTRIBUTION OF GABA-LIKE IMMUNOREACTIVITY}

GABA-like immunoreactivity was observed in many neuropils of the cricket brain. Also intensely

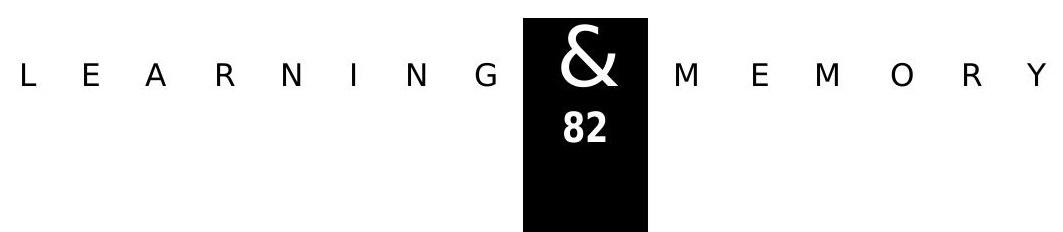




\section{GABA AND GABA RECEPTOR DISTRIBUTION IN CRICKET BRAIN}
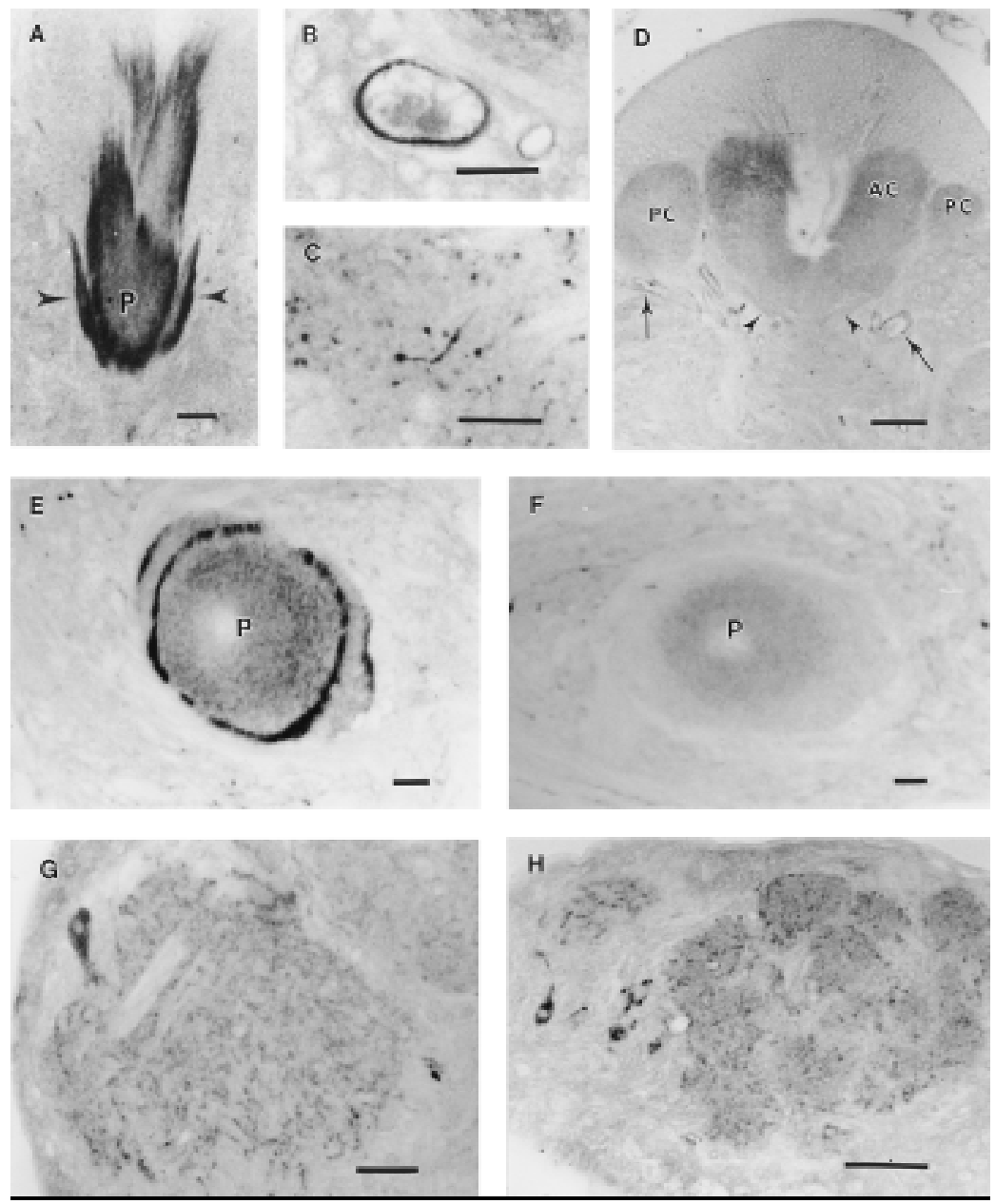

Figure 3: Developmental aspects of RDL-like GABA receptors in the cricket brain. (A) Frontal section through the anterior calyx of a 5-day-old adult. An intense GABAR immunoreactivity is visible in the inner part of the calyx and at the proximal part of the peduncle $(P)$, as well as in the two arms (arrowheads) of the posterior calyx. (B) Detail of a tracheal cell from a newly emerged adult. The inner part shows a strong immunoreactivity. (C) D etail of a labeled glial cell in the lateral protocerebrum of a 5-day-old adult. $(D)$ Frontal section through the calyx of a newly emerged adult. N either the inner part of the anterior calyx (AC), nor the arms (arrowheads) of the posterior calyx (PC) show any label. In newly emerged adults, the main immunoreactive structures are the tracheal cells (arrows). (E) Section through the peduncle of a 5-day-old adult. $\mathrm{N}$ ote the concentric immunoreactive rings surrounding the peduncle $(P)$, which is diffusely and concentrically stained. $(F)$ Section through the peduncle of a newly emerged adult. Although a pale diffuse label can be seen in the peduncle $(\mathrm{P})$, the peripheral processes, strongly labeled in $E$, cannot be evidenced. $(G)$ Frontal section through the antennal motor center. Immunoreactive processes invade the neuropil. O ne of the four labeled perikarya is visible. $(H)$ Section through the antennal lobe. A network of labeled profiles appears in the glomeruli, at the external margin of deutocerebrum, a labeled neuron is present. $(A-C, H)$ bar, 25 $\mu \mathrm{m} ;(D, G)$ bar, $5 \mu \mathrm{m} ;(E, F)$ bar, $10 \mu \mathrm{m} ;(D, G)$ bar, $50 \mu \mathrm{m} ;(E, F)$ bar, $10 \mu \mathrm{m}$.

labeled neuronal cell body clusters were abundant and their distribution is summarized Figure 1.

\section{PROTOCEREBRUM}

\section{Mushroom Bodies}

Kenyon cells did not exhibit GABA-like immunoreactivity. However, a dense network of immunoreactive processes invaded the anterior and posterior calyces (Fig. 4A,B). Immunoreactive fibers of large diameter were found at the entrance of the posterior calyx (Fig. 4A). The upper part of the peduncle contained immunoreactive arborizations and was surrounded by large fibers strongly immunostained (Fig. 4G). The GABA-like immunoreactivity was poorly represented in the distal part of the peduncle. In the lobes, the distribution of immu- noreactivity was not homogeneous. Densely stained fibers originating from the protocerebrocalycal tract (PCT) entered the $\alpha$ lobe (Fig. 4I), which was more densely labeled than the $\beta$ lobe. The dorsal part of the $\beta$ lobe was not immunoreactive, but some large labeled fibers entered its ventral portion (Fig. 4J)

\section{Central Complex}

The protocerebral bridge and the noduli were not immunostained (data not shown). The fanshaped body (Fig. 4D) was divided into eight segments and immunoreactive tracts invaded the ellipsoid body, producing dense staining (Fig. 4E). Immunoreactive fascicles were identified surrounding the central complex, as was also the case for the superior protocerebral commissure, and the subcentral body commissure (Fig. 4D). 
Strambi et al.
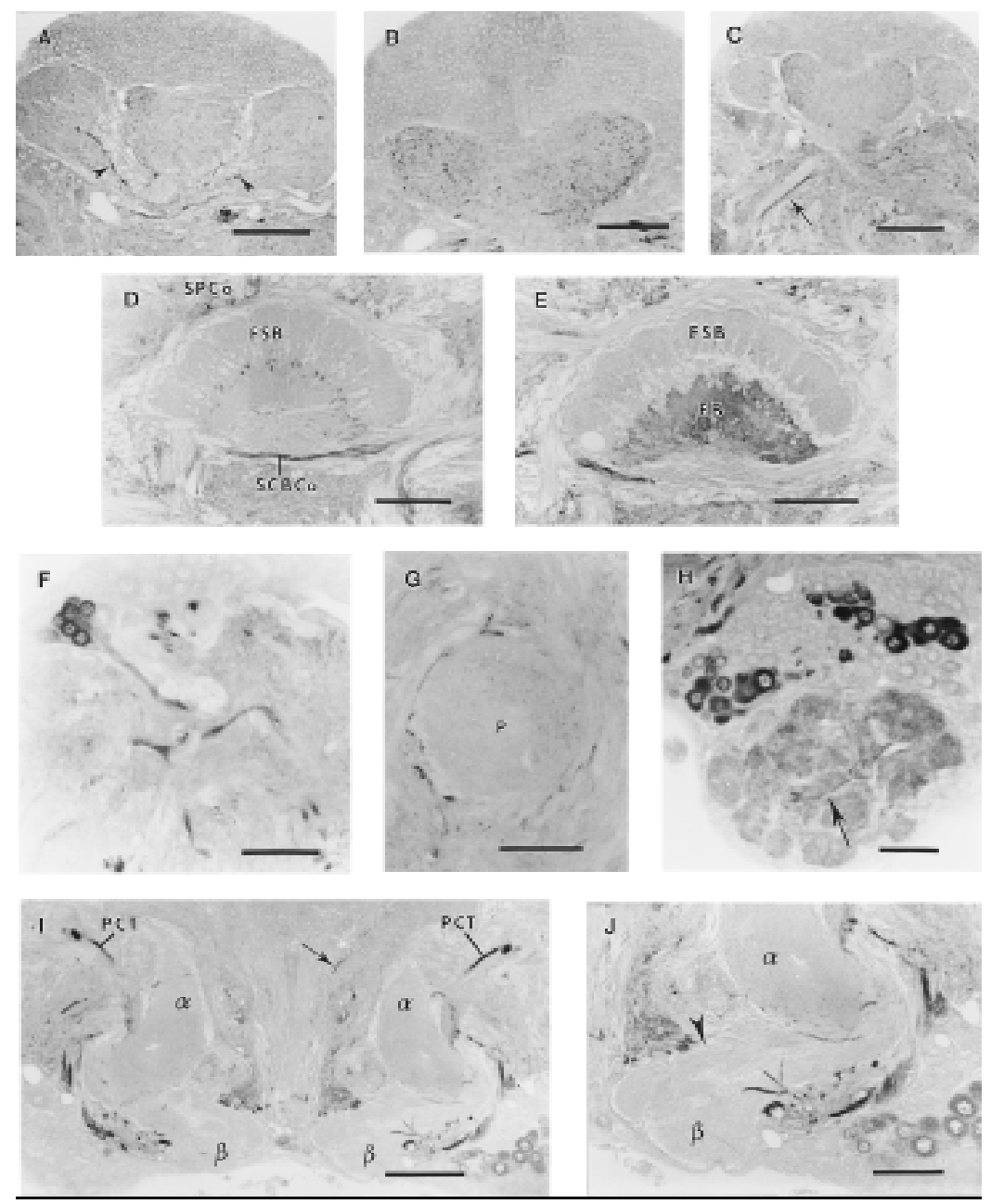

Figure 4: GABA-like immunoreactivity in the cricket brain. (A) Frontal section of the calyx. Large immunoreactive fibers (arrowheads) run along the arms of the posterior calyx (PC). (B) Detail of immunoreactive processes in the anterior caIyx neuropil. (C) Frontal section showing the antennoglomerular tract (arrow) where external immunoreactive fibers appear. (D) Section through the central body. Immunoreactive processes divide the fan-shaped body into eight segments (FSB). The superior protocerebral commissure (SPCo) and the subcentral body commissure (SCBCo) are strongly labeled. (E) Section through the ellipsoid body (EB), which is densely immunoreactive as compared to the fan-shaped body (FSB). Immunoreactive fibers are visible in the isthmus tract. $(F)$ Group of immunoreactive neurons (Fig. 1 group VII), sending their axons to the protocerebrocalycal tract (PCT). (G) Section through the peduncle (P). Immunoreactive processes are present in the peduncle, which is surrounded by large, strongly labeled fibers. (H) Section through the deutocerebrum. Numerous neurons of the antennal lobe present a dense label. The glomeruli are immunoreactive and labeled fibers are joining some of them (arrow). (I) Frontal section through the $\alpha(\alpha)$ and $\beta(\beta)$ lobes of mushroom bodies. The PCT is strongly labeled and sends arborizations in the two lobes. Immunoreactive fibers are also present in the median bundle (arrow). (V) Immunoreactive fibers entering the $\alpha$ and $\beta$ lobes of the mushroom body. The dorsal part of the $\beta$ lobe (arrowhead) is free of any labeling. $(A-E, G, I) B a r, 100$ $\mu \mathrm{m} ;(F, H, J)$ bar, $50 \mu \mathrm{m}$.

Immunoreactivity was also found in the isthmus tract.

\section{Other Neuropils and Tracts}

A network of immunoreactive processes invaded the dorsolateral and ventrolateral protocerebrum. Immunoreactive fibers were flanking the antennoglomerular tract, the main fiber group of which remained unlabeled (Fig. 4C). The deutocerebral commissure interconnecting the two antennal lobes was also strongly immunoreactive.

The PCT, which connects the lobes and the calyces of the mushroom bodies, was strongly labeled (Fig. 4I). In the lateral protocerebrum, a group of $\sim 85$ small cell bodies and a large giant neuron intensely stained (Fig. 4F) projected into the PCT.

\section{DEUTOCEREBRUM}

The antennal nerve did not show GABA-like immunoreactivity. However, the antennal motor center showed homogeneous dense labeling. A group of $\sim 30$ neurons at the ventral and internal edge of deutocerebrum were found to be strongly immunoreactive.

Glomeruli of the antennal lobe stained strongly, and were associated through immunoreactive fibers (Fig. 4H). About 230 labeled somata were present in the lateral and dorsomedial part of the antennal lobe (Fig. 4H).

\section{Discussion}

The RDL-like GABA receptors of A. domesticus

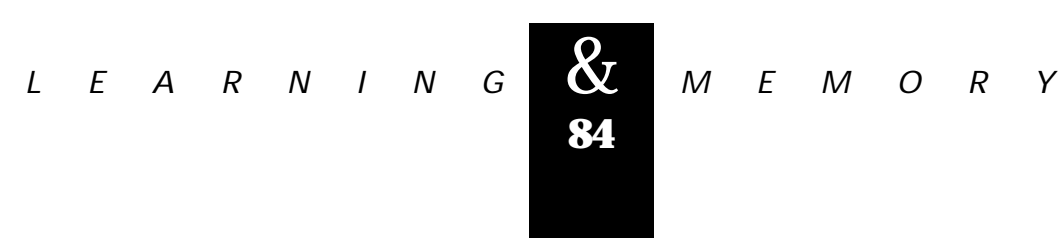


show a pattern of distribution in the brain ressembling that observed for other insect species. The deutocerebrum neuropils and especially the glomeruli of the antennal lobe stained strongly in Acheta as in Drosophila and Periplaneta (Aronstein and ffrench-Constant 1995, Harrison et al. 1996; Sattelle et al. 1998), indicating a major site of GABA-like receptors in processing of olfactory inputs to the nervous system. In this context, it is of interest to note the recent evidence from functional studies that antennal lobe neural activity in response to odors is sensitive to the $\mathrm{GABA}_{A}$ receptor blocker picrotoxin (Stopfer et al. 1997). In the central complex of Acheta, as in Drosophila (Aronstein and ffrench-Constant 1995; Harrison et al. 1996), only the ellipsoid body and the fibers originating from the protocerebral bridge were labeled, unlike the case of Periplaneta (Sattelle et al. 1998).

Neurons immunoreactive to the RDL-GABA receptor subunit antiserum were present in Periplaneta (Sattelle et al. 1998), although less numerous, labeled cells with similar localization were seen in Acheta. Interestingly in Acheta, the labeling of glial cells in specific neuropils was detected, these included the dorsolateral and ventrolateral neuropils, which receive the lateral protocerebral bundle originating from the antenno-glomerular bundle. This underlines the importance of the RDL-like GABA receptor subunit in these neuropils, and suggests possible roles for GABA receptors in glial cells. The labeling of tracheal cells in newly emerged adults was unexpected and a possible explanation may be sought in earlier morphological observations, which led Hoyle (1986) to consider insect tracheal cells as closely related to glial cells. The functions of putative nonneuronal RDL-like receptors remain to be determined.

Compared to Drosophila and Periplaneta, the most striking feature in Acheta is the intense immunoreactivity of the upper part of the peduncle of mushroom bodies, where the putative GABA receptors are localized preferentially on fiber fascicles invading the calyces. In a recent paper, Brotz et al. (1997) investigated the distribution of GABA receptors in Calliphora mushroom bodies. As in Acheta, immunoreactive fibers exiting the calyx and forming distinct fascicles were observed in the peduncle. The two strongly stained fiber tracts surrounding the peduncle seem to be specific to Acheta. In contrast to Calliphora, the GABA receptors in Acheta lobes are less numerous, based on the intensity of immunoreactive labeling, and appear to be more dense at the periphery than at the center of the lobes. All these results are in agreement with recent data demonstrating that the RDLlike GABA receptor was confined to neuropils; in contrast to $\mathrm{LCCH} 3$ receptor-like subunit which was represented in developing neuroblasts and in adult neuronal cell bodies (Aronstein et al. 1996).

The pattern of GABA-like immunoreactivity in the cricket brain shows many similarities with the findings in A. domesticus (Schürmann 1987), M sexta (Hoskins et al. 1986; Homberg et al. 1987), P. americana (Füller et al. 1989; Bleschschmidt et al. 1990), and A. mellifera (Bicker et al. 1985; Schäfer and Bicker 1986). The main groups of labeled cell bodies previously described in other species have a similar distribution, although the number of neurons seems to be low er in the cricket. Glomeruli of the antennal lobe are strongly labeled, as well as the ellipsoid body of the central complex.

Among the immunostained fascicles of the brain, the most prominent is the PCT that exhibits an intense reactivity throughout its course. As in A. mellifera, M sexta, S. americana, and Locusta migratoria (Hoskins et al. 1986; Schäfer and Bicker 1986; Leitch and Laurent 1996; Seidel and Bicker 1997), the axons of the antennoglomerular tract are not immunoreactive but are surrounded by large labeled fibers. Interestingly, the large diameter, strongly immunoreactive fibers that surround the upper part of the peduncle and enter the posterior calyx seem to correspond to those described in the mushroom bodies of S. americana (Leitch and Laurent 1996); they probably originate from the PCT.

From our studies it appears that GABA and GABA receptors show a similar distribution in brain structures known to be involved in learning and memory. Such is the case for the olfactory glomeruli of the antennal lobe, as well as for fascicles connecting the antennal lobe to mushroom bodies (antennoglomerular tract) and projecting in some particular neuropils (dorso- and ventrolateral protocerebrum). Similarly, GABA and GABA receptors are present together in the ellipsoid body and in connecting fibers of the central complex. Central complex Drosophila mutants have been show $\mathrm{n}$ to present deficiencies in olfactory learning (Heisenberg et al. 1985), and this structure could play a role in sensory and motor integration (Heisenberg 1994; Homberg 1994; Heisenberg et al. 1995). Moreover, the prominent and concomitant distribution of GABA and GABA receptors in particular areas of mushroom bodies underlines the importance of GABAergic inhibitory signals, which

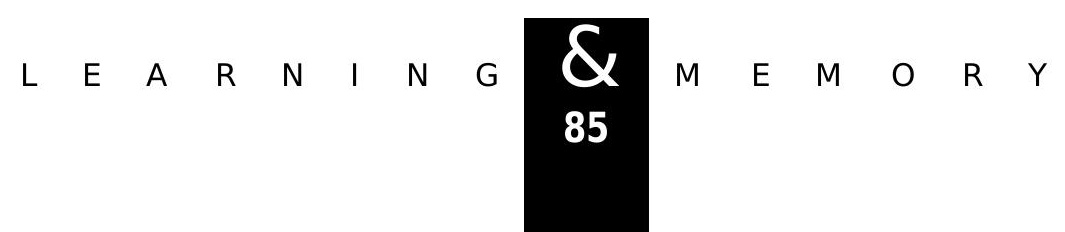


Strambi et al.

contribute to information processing in this brain integrative center.

Of importance are the data collected in mushroom bodies. It is now well known that Kenyon cells do not show GABA immunoreactivity either in their somata or in their axons and dendrites (Leitch and Laurent 1996). Up to now, it is only in honeybees that a taurine-like immunoreactivity was observed in the intrinsic neurons of mushroom bodies (Schäfer et al. 1988) and that a subset of Kenyon cell somata was seen to contain glutamate-like immunoreactivity (Bicker et al. 1988). Our results confirm that cricket Kenyon cells do not contain GABA. However, GABA receptors are present on the somata of the intrinsic neurons of mushroom bodies as detected either by immunocytochemistry (this study) or evidenced by patchclamp and ion imaging studies on cell-cultured Kenyon cells (Cayre et al. 1998). The rich GABAlike immunoreactivity detected in the calyces, the arms of the posterior calyx, and the upper part of the peduncle, together with the dense population of RDL-like GABA receptors present in the same locations underlines the major importance of GABA as an inhibitory neurotransmitter in these parts of mushroom body regions. The role of GABA in the control of oscillating neuronal ensembles has been underlined in odor perception (Laurent et al. 1996; Stopfer et al. 1997), thus it is tempting to postulate a similar function for GABA in the control of Kenyon cell excitability.

Data obtained after cobalt filling (M. Cayre, C. Strambi, and A. Strambi, unpubl.), seem to indicate that median Kenyon cells, mainly originating from the progeny of adult-persistent neuroblasts (Cayre et al. 1994, 1996a), send numerous arborizations to the calyces, especially to the posterior calyx, and project their axons to the periphery of the peduncle. The strong label observed on the arms of the posterior calyx and around the peduncle either by cobalt filling or by immunocytochemical detection of the RDL-like GABA receptor, raises the question of preferential distribution of GABAR on adult born neurons. Moreover, recent in vitro studies of Acheta mushroom bodies pointed out a heterogeneity in the populations of Kenyon cells with respect to neurotransmitter receptor expression (Cayre et al. 1998). Taken together these data could support the hypothesis of functional subdivision of Kenyon cell populations proposed for Calliphora (Brotz et al. 1997). In vertebrates, it is now well-known that GABAergic neurons also express GABA receptors (Gao et al. 1993; Nüsser et al. 1995). Thus, it could be postulated that the large fibers exhibiting a strong GABA-like immunoreactivity that surround the peduncle and enter the two arms of the posterior calyx should also bear GABA receptors. Such an hypothesis is not supported by our findings because these fibers seem mostly to originate from the PCT (Schildberger $1983,1984)$ that is free from any label using the RDL-like GABA receptor antiserum. How ever, to establish this, studies on the subcellular localization of GABA and GABA receptors would be required. It has been shown in $M$ sexta that the expression of GABA-like immunoreactivity changed during postembryonic development and a possible role for ecdysteroids in the regulation of GABA synthesis has been suggested (Homberg and Hildebrand 1994). In the present work, preliminary observations evidenced that RDL-like GABA receptors are absent in the nervous tissue during the first day of imaginal life. Further studies will examine whether hormones, which are known to act in the cricket on progenitors of Kenyon cells (Cayre et al. 1994, 1997a), are also modulating the expression of GABA receptors.

Recent findings induce to compare insect mushroom bodies with the vertebrate hippocampus, a brain structure involved in learning and memory (Jarrard 1995). The presence of a form of long-term potentiation in the honeybee mushroom bodies (Oleskevich et al. 1997), as well as structural similarities (Mizunami et al. 1993), have also been noted. Moreover, the hormonally modulated neurogenesis observed in cricket mushroom bodies presents similarities with the cell proliferation and migration observed in a particular part of the hippocampus, the dentate gyrus (Gould and Cameron 1996). It must be remembered that a dense GABAergic innervation characterize the rat hippocampus (Freund and Buzsaki 1996), and it has also been show $n$ that the molecular layer of the dentate gyrus was especially rich in $\mathrm{GABA}_{\mathrm{A}}$ receptors (Sperk et al. 1997).

Our present data underline functional parallels that exist between vertebrate hippocampus and invertebrate mushroom bodies. They also point out the importance of GABA inhibitory signals in brain structures, which are major integrative centers contributing to information processing.

\section{Acknowledgments}

This work was partly supported by a research training

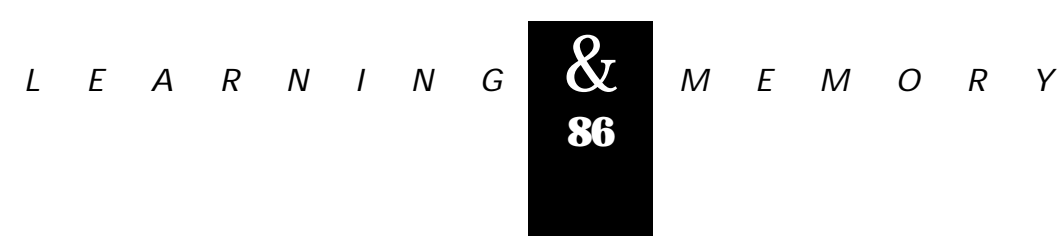


grant of the European Commission, and by the CNRS and the Biotechnology and Biological Scientific Research Council. The publication costs of this article were defrayed in part by payment of page charges. This article must therefore be hereby marked "advertisement" in accordance with 18 USC section 1734 solely to indicate this fact.

\section{References}

Aronstein, K. and R. ffrench-Constant. 1995.

Immunocytochemistry of a novel GABA receptor subunit $R d l$ in Drosophila melanogaster. Invertebr. Neurosci. 1: 25-31.

Aronstein, K., V. Auld, and R. ffrench-Constant. 1996. Distribution of two GABA receptor-like subunits in the Drosophila CNS. Invertebr. Neurosci. 2: 115-120.

Bicker, G., S. Schäfer, and T.G. Kingan. 1985. Mushroom body feedback interneurons in the honeybee show GABA-like immunoreactivity. Brain Res. 360: 394-397.

Bicker, G., S. Schäfer, O.P. O ttersen, and J. Storm-M athisen. 1988. Glutamate-like immunoreactivity in identified neuronal populations of insect nervous system. J. Neurosci.

8: 2108-2122.

Bleschschmidt, K., M. Eckert, and H. Penzlin. 1990. Disribution of GABA-like immunoreactivity in the central nervous system of the cockroach Periplaneta americana (L.). J. Chem. Neuroanat. 3: 323-336.

Brotz, T.M., B. Bochenek, K. Aronstein, R.H. ffrench-Constant, and A. Borst. 1997. Gamma-aminobutyric acid receptor distribution in the mushroom bodies of a fly (Calliphora erythrocephala): A functional subdivision of Kenyon cells? J. Comp. Neurol. 383: 42-48.

Cayre, M., C. Strambi, and A. Strambi. 1994. Neurogenesis in an adult insect brain and its hormonal control. Nature 368: $57-59$.

Cayre, M., C. Strambi, P. Charpin, R. Augier, M.R. Meyer, J.S. Edwards, and A. Strambi. 1996a. Neurogenesis in adult insect mushroom bodies. J. Comp. Neurol. 371: 300-310.

Cayre, M., C. Strambi, P. Charpin, R. Augier, M. Renucci, and A. Strambi. 1996b. Inhibition of polyamine biosynthesis alters oviposition behavior in female crickets. Behav. Neurosci. 110: 1117-1125.

Cayre, M., C. Strambi, P. Charpin, R. Augier, and A. Strambi. 1997a. Inhibitory role of ecdysone on neurogenesis and polyamine metabolism in the adult cricket brain. Arch. Insect Biochem. Physiol. 35: 85-97.

- - - 1997b. Specific requirement of putrescine for the mitogenic action of juvenile hormone on adult insect neuroblasts. Proc. Natl. Acad. Sci. 94: 8238-8242.

Cayre, M., S.D. Buckingham, S. Yagodin, and D.B. Sattelle. 1998. Cultured mushroom body neurons from an adult insect express functional receptors for five major neurotransmitters. J. Neurophysiol. (in press).
Chen, R., D. Belelli, J.J. Lambert, J.A. Peters, A. Reyes, and N.C. Lan. 1994. Cloning and functional expression of a Drosophila $\gamma$-aminobutyric acid receptor. Proc. Natl. Acad. Sci. 91: 6069-6073.

Davis, R. 1993. Mushroom bodies and Drosophila learning. Neuron 11: 1-14.

- - . 1996. Physiology and biochemistry of Drosophila learning mutants. Physiol. Rev. 76: 299-317.

de Belle, J.S. and M. Heisenberg. 1994. Associative odor learning in Drosophila abolished by chemical ablation of mushroom bodies. Science 263: 692-695.

Erber, J., T. Mashur, and R. Menzel. 1980. Localization of short-term memory in the brain of the bee, Apis mellifera. Physiol. Entomol. 5: 343-358.

Fahrbach, S.E. and G.E. Robinson. 1996. Juvenile hormone, behavioral maturation, and brain structure in the honeybee. Dev. Neurosci. 18: 102-114.

ffrench-Constant, R.H., D.P. M ortlock, C.D. Shaffer, R.J. Maclntyre, and R.T. Roush. 1991. Molecular cloning and transformation of cyclodiene resistance in Drosophila: An invertebrate $\gamma$-aminobutyric acid subtype A receptor locus. Proc. Natl. Acad. Sci. 88: 7209-7213.

Freund, T.F. and G. Buzsaki. 1996. Interneurons of the hippocampus. Hippocampus 6: 347-470.

Füller, H., M. Eckert, and K. Blechschmidt. 1989. Distribution of GABA-like immunoreactive neurons in the optic lobes of Periplaneta americana. Cell Tissue Res. 255: 225-233.

Gao, B., J.M. Fritschy, D. Benke, and H. Mohler. 1993. Neuron-specific expression of $\mathrm{GABA}_{A}$-receptor subtypes: Differential association of the $\alpha_{1}$ - and $\alpha_{3}$-subunits with serotonergic and GABAergic neurons. Neurosci.

54: 881-892.

Gould, E. and H.A. Cameron. 1996. Regulation of neuronal birth, migration and death in the rat dentate gyrus. Dev. Neurosci. 18: 22-35.

Han, P.L., L.R. Levin, R.R. Reed, and R.L. Davis. 1992. Preferential expression of the Drosophila rutabaga gene in mushroom bodies, neural centers for learning in insects. Neuron 9: 619-627.

Hammer, M. 1997. The neural basis of associative reward learning in honeybees. Trends Neurosci. 20: 245-252.

Hammer, M. and R. Menzel. 1995. Learning and memory in the honeybee. J. Neurosci. 15: 1617-1630.

Harrison, J.B., H.H. Chen, E. Sattelle, P.J. Barker, N.S. Huskisson, J.J. Rauh, D. Bai, and D.B. Sattelle. 1996. Immunocytochemical mapping of a C-terminus anti-peptide antibody to the GABA receptor subunit, RDL, in the nervous 
Strambi et al.

system of Drosophila melanogaster. Cell Tissue Res. 284: 269-278.

Harvey, R.J., B. Schmitt, I. Hermans-Borgmeyer, E.D. Gundelfinger, H. Betz, and M.G. Darlison. 1994. Sequence of a Drosophila ligand-gated ion-channel polypeptide with an unusual amino-terminal extracellular domain. J. Neurochem. 62: 2480-2483.

Heisenberg, M. 1994. Central brain function in insects: Genetic studies on the mushroom bodies and central complex in Drosophila. In Progress in zoology (ed. K. Schildberger and N. Eisner), 39: pp. 61-79. Verlag, Stuttgart, Germany.

Heisenberg, M., A. Borst, S. Wagner, and D. Byers. 1985. Drosophila mushroom body mutants are deficient in olfactory learning. J. Neurogenet. 2: 1-30.

Heisenberg, M., M. Heusipp, and C. Wanke. 1995. Structural plasticity in the Drosophila brain. J. Neurosci.

15: 1951-1960.

Henderson, J.E., D.M. Soderland, and D.C. Knipple. 1993. Characterization of a putative gamma-aminobutyric-acid (GABA) receptor beta-subunit gene from Drosophila melanogaster. Biochem. Biophys. Res. Comm. 193: 474-482.

Homberg, U. 1987. Structure and functions of the central complex in insects. In Arthropod brain: Its evolution, development, structure, and functions (ed. A.P. Gupta) pp. 347-367. Wiley, New York, NY.

- - . 1994. Distribution of neurotransmitters in the insect brain. In Progress in zoology (ed. W. Rathmayer), pp. 1-88. Verlag, Stuttgart, Germany.

Homberg, U. and J.G. Hildebrand. 1994. Postembryonic development of $\gamma$-aminobutyric acid like immunoreactivity in the brain of the sphinx moth Manduca sexta. J. Comp. Neurol. 339: 132-149.

Homberg, U., T.G. Kingan, and J.G.Hildebrand. 1987. Immunocytochemistry of GABA in the brain and suboesophageal ganglion of Manduca sexta. Cell Tissue Res. 248: 1-24.

Hoskins, S.G., U. Homberg, T.G. Kingan, T.A. Christensen, and J.G. Hildebrand. 1986. Immunocytochemistry of GABA in the antennal lobe of the sphinx moth Manduca sexta. Cell Tissue Res. 244: 243-252.

Hoyle, G. 1986. Glial cells of an insect ganglion. J. Comp. Neurol. 246: 85-103.

Jarrard, L.E. 1995. What does the hippocampus really do ? Behav. Brain Res. 71: 1-10.

Laurent, G. and H. Davidowitz. 1994. O dorant-induced oscillations in the mushroom bodies of the locust. J. Neurosci. 14: 2993-3004.

Laurent, G., M. Wehr, and H. Davidowitz. 1996. Temporal representations of odors in an olfactory network. J. Neurosci. 16: 3837-3847.

Leitch, B. and G. Laurent. 1996. GABAergic synapses in the antennal lobe and mushroom body of the locust olfactory system. J. Comp. Neurol. 372: 487-514.

Macdonald, R.L. and R.W. O Isen. 1994. GABA $A_{A}$ receptor channels. Annu. Rev. Neurosci. 17: 569-602.

McKernan, R.M. and P.J. Whiting. 1996. Which GABA receptor subtypes really occur in the brain? Trends Neurosci. 19: 139-143.

Mauelshagen, J. 1993. Neural correlates of olfactory learning in an idenfied neuron in the honeybee brain. J. Neurophysiol. 69: 609-625.

Mizunami, M., J.M. Weibrecht, and N.J. Strausfeld. 1993. A new role for the insect mushroom bodies: Place memory and motor control. In Biological neural networks in invertebrate neuroethology and robotics (ed. R.D. Breer, R.E. Ritzman, and T. McKenna), pp. 199-225. Academic Press, New York, NY.

Nighorn, A., M.J. Healy, and R.L. Davis. 1991. The cyclic AMP phosphodiesterase encoded by the Drosophila dunce gene is concentrated in the mushroom body neuropil. Neuron 6: 455-467.

N üsser, Z., D.B. Roberts, A. Baude, J.G. Richards, W . Sieghert, and P. Somogyi. 1995. Immunocytochemical localization of the alphal and beta2/3 subunits of the $\mathrm{GABA}_{\mathrm{A}}$ receptor in relation to specific GABAergic synapses in the dentate gyrus. Eur. J. Neurosci. 7: 630-646.

Oleskevich, S, J.D. Clements, and M.V. Srinivasan. 1997. Long-term synaptic plasticity in the honeybee. J. Neurophysiol. 78: 528-532.

Sattelle, D.B. 1990. GABA receptors of insects. Adv. Insect Physiol. 22: 1-113.

Sattelle, D.B., S.C.R. Lummis, J.F.H. W ong, and J.J. Rauh. 1991a. Pharmacology of insect GABA receptors. Neurochem. Res. 16: 363-374.

Sattelle, D.B., J. Marshall, S.C.R. Lummis, C.A. Leech, K.W.P. Miller, N.M.A. Anthony, D. Bai, K.A. W afford, J.B. Harrison, L.A. Chapaitis, M.K. W atson, E.A. Benner, G. Vassallo, J.F.H. Wong, and J.J. Rauh. 1991b. $\gamma$-Aminobutyric acid and L-glutamate receptors of insect nervous tissue. In Transmitter amino acid receptors: Structures, transduction and models for drug development (ed. E.A. Barnard and E. Costa), pp. 273-291. Thieme Medical Publishers, New York, NY.

Sattelle, D.B., H.H. Harrison, D. Chen, D. Bai, and M. Takeda. 1998. Immunocytochemical localization of GABA receptors in the head ganglia of Periplaneta americana. Neuroscience Lett. (in press).

Schäfer, S. and G. Bicker. 1986. Distribution of GABA-like

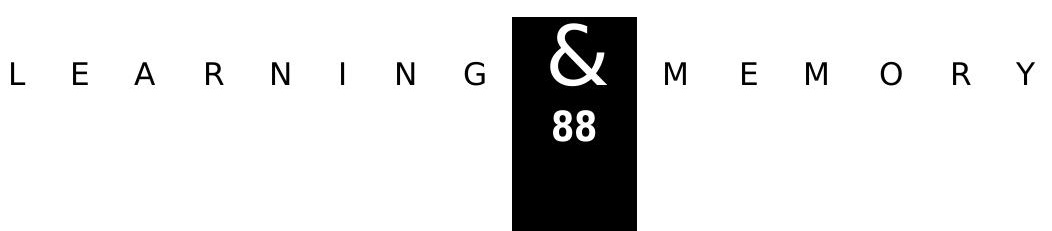




\section{GABA AND GABA RECEPTOR DISTRIBUTION IN CRICKET BRAIN}

imunoreactivity in the brain of the honeybee. J. Comp. Neurol. 246: 287-300.

Schäfer, S., G. Bicker, O .P. O ttersen, and J. Storm-M athisen. 1988. Taurine-like immunoreactivity in the brain of the honeybee. J. Comp. Neurol. 268: 60-70.

Schildberger, K. 1983. Local interneurons associated with the mushroom bodies and the central body in the brain of Acheta domesticus. Cell Tissue Res. 230: 573-586.

- - - 1984. Multimodal interneurons in the cricket brain: Properties of identified extrinsic mushroom body cells. J. Comp. Physiol. 154: 71-79.

Schürmann, F.W. 1970. Über die Struktur der Pilzkörper des Insektenhirns. I. Synapsen im Pedunculus. Z. Zellforsch. 103: 365-381.

- - - 1972. Über die Struktur der Pilzkörper des Insektenhirns II Synaptische Schaltungen im Alpha-Lobus des Heimchens Acheta domesticus L. Z. Zellforsch. 127: $240-257$.

- - . 1973. Über die Struktur der Pilzkörper des Insektenhirns III Die Anatomie der Nervenfasern in den Corpora pedunculata bei Acheta domesticus L. (O rthoptera): Eine Golgi studie. Z. Zellforsch. 145: 247-285.

- - - 1974. Bemerkungen zur Funktion der Corpora pedunculata im Gehirn der Insekten aus morphologischer Sicht. Exp. Brain Res. 19: 406-432.

- - . 1987. The architecture of the mushroom bodies and related neuropiles in the insect brain. In Arthropod brain: Its evolution, development, structure, and functions (ed. A.P. Gupta), pp. 231-264. Wiley, New York, NY.

Seidel, C. and G. Bicker. 1997. Colocalization of NADPH-diaphorase and GABA-immunoreactivity in the olfactory and visual system of the locust. Brain Res. 769: 273-280.

Sieghart, W. 1995. Structure and pharmacology of $\gamma$-aminobutyric acid $_{\mathrm{A}}$ receptor subtypes. Pharmacol. Rev. 47: 181-234.

Skoulakis, E.M., D. Kalderon, and R.L. Davis. 1993. Preferential expression in mushroom bodies of the catalytic subunit of protein kinase $A$ and its role in learning and memory. Neuron 11: 197-208.

Sperk, G., C. Schwarzer, K. Tsunashima, K. Fuchs, and W . Sieghart. 1997. $\mathrm{GABA}_{\mathrm{A}}$ receptor subunits in the rat hippocampus I: Immunocytochemical distribution of 13 subunits. Neuroscience 80: 987-1000.

Stopfer, M., S. Bhagavan, B.H. Smith, and G. Laurent. 1997. Impaired odour discrimination on desynchronization of odour-encoding neural assemblies. Nature 390: 70-74.

Technau, G. 1984. Fiber number in the mushroom bodies of adult Drosophila melanogaster depends on age, sex and experience. J. Neurogenet. 1: 113-126.

Tu, Z. and H.H. Hagedorn. 1992. Purification and characterization of pyruvate carboxylase from the honeybee and some properties of related biotin-containing proteins in other insects. Arch. Insect Biochem. Physiol. 19: 53-66.

Weiss, M.J. 1981. Structural patterns in the corpora pedunculata of Orthoptera: A reduced silver analysis. J. Comp. Neurol. 203: 515-533.

Williams, J.L.D. 1975. Anatomical studies of the insect central nervous system: A ground-plan of the midbrain and an introduction to the central complex in the locust, Schistocerca gregaria (O rthoptera). J. Zool. Lond. 176: 67-86.

Withers, G.S., S.E. Fahrbach, and G.E. Robinson. 1995. Effects of experience and juvenile hormone on the organization of mushroom bodies in honey bees. J. Neurobiol. 26: 130-144.

Witten, J.L. and J.W. Truman. 1991. The regulation of transmitter expression in postembryonic lineages in the moth Manduca sexta. II Role of cell lineage and birth order. J. Neurosci. 11: 1990-1997.

Ziegler, R., D.L. Engler, and N.T. Davis. 1995. Biotin-containing proteins of the insect nervous system, a potential source of interferences with immunocytochemical localization procedures. Insect Biochem. Mol. Biol. 25: 569-574.

Received January 9, 1998; accepted in revised form April 24, 1998.

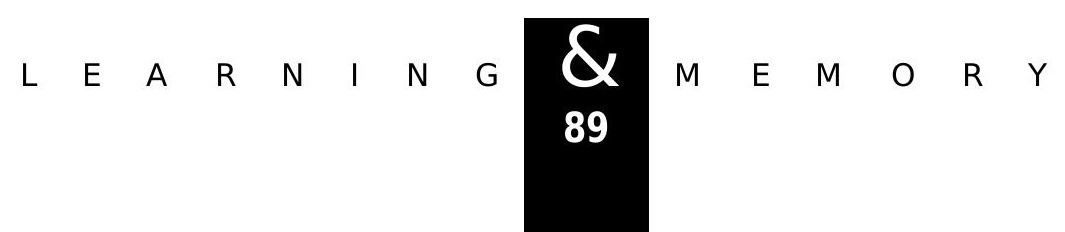




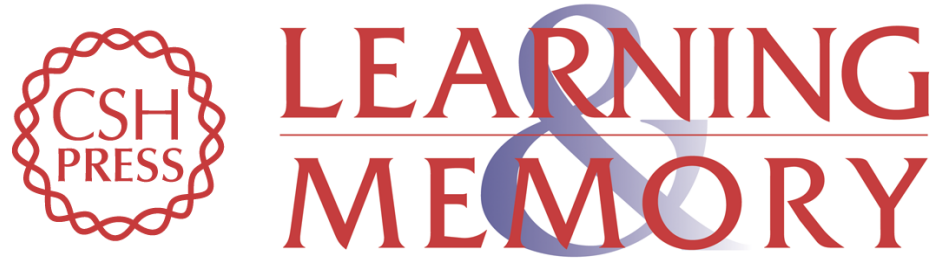

\section{Immunocytochemical Mapping of an RDL-Like GABA Receptor Subunit and of GABA in Brain Structures Related to Learning and Memory in the Cricket Acheta domesticus}

Colette Strambi, Myriam Cayre, David B. Sattelle, et al.

Learn. Mem. 1998, 5:

Access the most recent version at doi:10.1101//m.5.1.78

References This article cites 64 articles, 10 of which can be accessed free at: http://learnmem.cshlp.org/content/5/1/78.full.html\#ref-list-1

License

Email Alerting

Receive free email alerts when new articles cite this article - sign up in the box at the Service top right corner of the article or click here. 